\title{
Lack of Publication Bias in Intelligence and Working Memory Research: Reanalysis of Ackerman, Beier, \& Boyle, 2005
}

\author{
Maciej Taraday \\ Institute of Psychology, Jagiellonian University, Poland
}

\begin{abstract}
A meta-analysis was carried out to demonstrate the existence of publication bias in research on the relationship between measures of fluid intelligence and working memory. Reanalysis of data collected in Ackerman, Beier, \& Boyle, 2005 was conducted. A heterogeneous distribution of correlation coefficients in the absence of asymmetry in the distribution of coefficients was observed. According to the author of the analysis, there are no arguments for the presence of publication bias in this particular set of results drawn from research on intelligence and working memory.
\end{abstract}

Key words: fluid intelligence, working memory, meta-analysis, publication bias

\section{Introduction}

Measures of fluid intelligence moderately correlate with wide repertoire of intellectual abilities. This well-known phenomenon is called positive manifold (Spearman, 1904). However, the relationship between measures of working memory and fluid intelligence is mostly known in the realm of cognitive psychology. Estimates of common variance of working memory capacity and fluid intelligence measures range from

Acknowledgement

This article was created as part of the research project 'Memory background of fluid intelligence: the role of information maintenance in primary memory and resistance to interference in secondary memory search based on contextual cues' (UMO-2012/07 / N / HS6 / 00446) financed by the National Science Centre Poland.

Correspondence concerning this article should be addressed to Mr. Maciej Taraday, Institute of Psychology, Jagiellonian University, ul. Ingardena 6, 30-060 Kraków, Malopolskie, Poland. E-mail: maciek.taraday@gmail.com

Received January 2, 2018
$50 \%$ (Kane, Hambrick, \& Conway, 2005) to $92 \%$ (Colom, Rebollo, Palacios, Juan-Espinosa, \& Kyllonen, 2004). As a result, working memory is asserted by some researchers as a base of fluid intelligence (Jensen, 1998; Colom, FloresMendoza, \& Rebollo, 2003; Engle, 2002). These strong correlations affect the imagination of the researchers, who may think that working memory and fluid intelligence are highly related or even identical. Working memory capacity also strongly correlates with the following intellectual abilities considered to be components of intelligence: comprehension (Daneman \& Carpenter, 1980), reasoning ability (Kyllonen \& Christal, 1990), and test results, which reflect intellectual capacity - the SAT (e.g., Turner \& Engle, 1989). It should be noted that there are no other candidates, besides working memory, so closely related to fluid intelligence (Kyllonen, 2002). Due to these facts, researchers might not be interested in reporting moderate correlation coefficients - since this resembles the positive manifold - and publish mostly results depicting strong correlations between working memory capacity and fluid intelligence measures. 
The hypothesis that fluid intelligence and working memory are identical has no theoretical justification. Even the ideal correlation $(R=$ 1) between two measures does not mean that the same mechanism is responsible for the variability of both measures. A good example of such a strong atheoretical correlation, from a slightly different field of science, is the relationship between chocolate consumption and the number of Nobel laureates in different populations (Messerli, 2012). The Pearson correlation coefficient in this case is equal to 0.79 . It is unreasonable to interpret this relationship as causal, although there are studies showing a positive effect of the consumption of flavonoids contained in chocolate on cognitive functioning (see Nurk, Refsum, Drevon, Tell, Nygaard, Engedal, \& Smith, 2002; Desideri, Kwik-Uribe, \& Grassi, 2012; Corti, Flammer, Hollenberg, \& Lüscher, 2009; Sorond, Lipsitz, Hollenberg, \& Fisher, 2008; Bisson, Nejdi, Rozan, Hidalgo, Lalonde, \& Messaoudi, 2008). The correlation is strong, but we do not have a theoretical model, which explains the linkage number of Nobel laureates to chocolate consumption. It can be presumed that this strong correlation is an effect of another variable, e.g. a socio-economic status. In countries characterized by wealth (people with high socio-economic status) there is a greater chance to conduct scientific research as well as to consume chocolate. Thus, even very high values of correlation coefficients between working memory capacity and fluid intelligence measures are not proof that we are dealing with the same phenomenon.

Leaving aside the issues of the mechanisms that are responsible for the observed strong correlations of working memory and fluid intelligence, let us consider this: Is there a phenomenon that can systematically overstate the value of correlation coefficients? The author suspects that correlation coefficients reported in the research on fluid intelligence and working memory are inflated due to these facts: researchers are interested in reporting strong relationships, since low correlations are explained as positive manifold. A higher value of correlation coefficient suggests that the factor is more important in the context of intelligence. Open Science Collaboration (2015) reported that replications usually end with the effects strength lower by half on average, compared to the original studies.

\section{Publication Bias}

Publication bias is the effect of the policy of scientific journals. Unfortunately, a large part of scientific publications is focused on publishing innovative results or simply those in which some effect has been demonstrated. In practice, this means that it is far easier to publish the results of a research, in which the null hypothesis has been rejected, than those in which null effect is presented. Research in which the null hypothesis has not been rejected is sometimes considered inconclusive, because it is not entirely clear whether the lack of effect is the result of a mistake in the research procedure, or there is, indeed, no relationship between the measured variables.

Since it is more likely to publish results in which the null hypothesis was rejected, researchers are more likely to prepare manuscripts of articles from research in which the null hypothesis was rejected. We deal with the socalled file drawer effect (Rosenthal, 1979); results in which the null hypothesis could not be rejected, more often go to the researcher's desk drawer and no one but the researcher himself, knows that such a study was carried out. One can imagine that in an extreme situation, some research is carried out repeatedly, and only the results in which the null hypothesis is rejected are published. If we use the conventional statistical test significance level $(\alpha=.05)$, then with 20 replications of a particular test procedure, we will obtain 1 result indicating the presence 
of an effect that does not actually exist (the socalled first type error). Therefore, it should be expected that in the literature we will face overrepresentation of the research, in which the null hypothesis was rejected, despite the lack of a given effect in reality.

The impact of publication bias is difficult to estimate. In order to estimate publication bias in psychology, a reproducibility project has been set up and conducted by Open Science Collaboration. The aim of the project is to replicate 100 studies published in the magazines of prestigious psychological journals, Psychological Science, Journal of Personality and Social Psychology, and Journal of Experimental Psychology: Learning, Memory, and Cognition. The first results of the project show that from the set of articles, which contains $97 \%$ of results with the null hypothesis rejected, only $36 \%$ of replications reproduced null rejections. Moreover, the strength of replication effects observed in replication is on average lower by half, compared to the original studies (Open Science Collaboration, 2015).

Gilbert, Pettigrew, and Wilson (2016) are critical in their approach to the results obtained by Open Science Collaboration. They argue that the conclusion drawn from the results of the reproducibility project actually supports the opposite conclusion. First of all, they accuse Open Science Collaboration of making a crucial mistake in the way research is selected for replication. The application of the criterion of replicating results from specific journals leads to obtaining an idiosyncratic data set, which is not representative of the typical results in psychology. Secondly, they claim that obtaining results for which only some of the effects are reproducible should not be surprising, since replications are carried out on samples that do not match the same population. In addition, using the wrong statistical procedure is lowering the power of the effects, states Gilbert and his collaborators.
The power of publication bias can be observed in the example of research for which all replications have been registered. Turner, Matthews, Linardatos, Tell, and Rosenthal (2008) have analyzed the collection of studies on the effectiveness of antidepressants registered by the US Food and Drug Administration. The Food and Drug Administration data show that 74 experimental studies were carried out. In 38 , the null hypothesis was rejected, while 36 failed to reject the null hypothesis. Then, the researchers checked what part of these results was published in scientific journals. It turned out that $37 / 38$ studies in which the effectiveness of antidepressants was shown and only 3 out of 36 in which no effect was demonstrated. This gross disproportion illustrates the strong publication bias: $97 \%$ of results were published in which the null hypothesis was rejected and only $8 \%$ of those in which the null hypothesis was not rejected.

A publication bias is a significant threat in the case of a meta-analysis, because it is possible that the meta-analysis is based on results in which there are no negative results (the null hypothesis could not be rejected). Thus, a false image of reality is obtained, despite the large number of research attempts. The way to determine if we are dealing with publication bias is to compare the distributions of estimators obtained in studies with their expected theoretical distributions. For this purpose, we use funnel plots, in which the effect size (on the horizontal axis) and the sample size or error of measurement are plotted. In the absence of publication bias, one should expect a set of points arranged in a symmetrical inverted funnel on the graph. An asymmetrical shape of the chart - the advantage of results in which high power was obtained in comparison with those of low power, is the premise for the belief that we are dealing with publication bias (Sterne, Sutton, Ioannidis, Terrin, Jones, \& Lau, 2011). 


\section{The Strength of the Gf - WMC Correlation}

The meta-analysis by Ackerman, Beier, and Boyle (2005) shows the relationship between the working memory capacity and fluid intelligence measures at 25\%. Oberauer, Schulze, Wilhelm, and Süß (2005) critically commented on Ackerman, Beier, and Boyle (2005), stressing the use of unappropriated fixed effect model in the metanalysis and unjustified selection of working memorytasks. Oberauer etal. (2005) decided that a re-analysis is necessary and undertook it within the appropriate statistical model. The relationship between fluid intelligence and working memory measures proved to be much stronger, accounting for $72 \%$ of the common variation. The authors of both previous meta-analysis did not analyze the results in terms of publication bias.

It should be noted that measures of the strength of the relationship between fluid intelligence and working memory are characterized by a wide confidence interval (average interval $=0.17$ based on data from the meta-analysis by Ackerman, Beier, and Boyle 2005). Considering the existence of publication bias in other areas of science, one should assume that research on fluid intelligence and working memory relationship is not free from this phenomenon. It can be assumed that inflated correlations coefficients are especially probable in the field of working memory and fluid intelligence research. Since fluid intelligence correlates moderately with wide repertoire of cognitive abilities, several influential papers claimed that working memory and fluid intelligence are identical or that working memory capacity is not isomorphic with fluid intelligence but that it is a very strong predictor of fluid intelligence.

\section{Method}

Reanalysis was conducted on Ackerman, Beier and Boyle (2005). All the analyses were conducted in R with package "metafor" (Viechtbauer, 2010). These data contain correlation coefficients taken from 57 publications (including 4 doctoral dissertations). The metaanalysis is based on 86 independent research trials, in which 9778 people took part. The data from 40 trials were classified in this analysis (all the coefficients were statistically significant). A theoretical criterion was used - the author used data, which represents the correlation between measures of intelligence and working memory capacity measures.

The purpose of this analysis is to examine the distribution of correlation coefficients between working memory measures and the test results used to measure fluid intelligence. The model was introduced with uncorrected correlation coefficients of fluid intelligence measures (Raven's test, $g$, reasoning measures: spatial, numerical and verbal), working memory capacity measures (verbal, numerical and spatial), number of individual samples, and standard error of estimation of the correlation coefficient.

\section{Results}

The analysis was conducted using a random effect model. Heterogeneity of estimators was observed $I^{2}=85.5 \%, Q(39)=387.2, p<0.0001$ $(A I C=-70.61, B I C=-67.29)$.

Figure 1 illustrates correlation coefficients in 40 samples subject to meta-analysis.

Pearson correlation coefficients between working memory capacity and $G f$ measures is on average equal to $.35, C I_{95} \%[.32, .38] ; s e=$ $.015, z=23.2, p<.0001$.

Figure 2 presents the relationship between the value of the correlation coefficient (horizontal axis) and the standard error of the measurement in a given sample (vertical axis). Correlation coefficients are distributed symmetrically around the value of .35 . The hypothesis of a zero asymmetry test in the funnel chart $(t=$ $-1.77, d f=38, p=.085$ ) could not be rejected. 


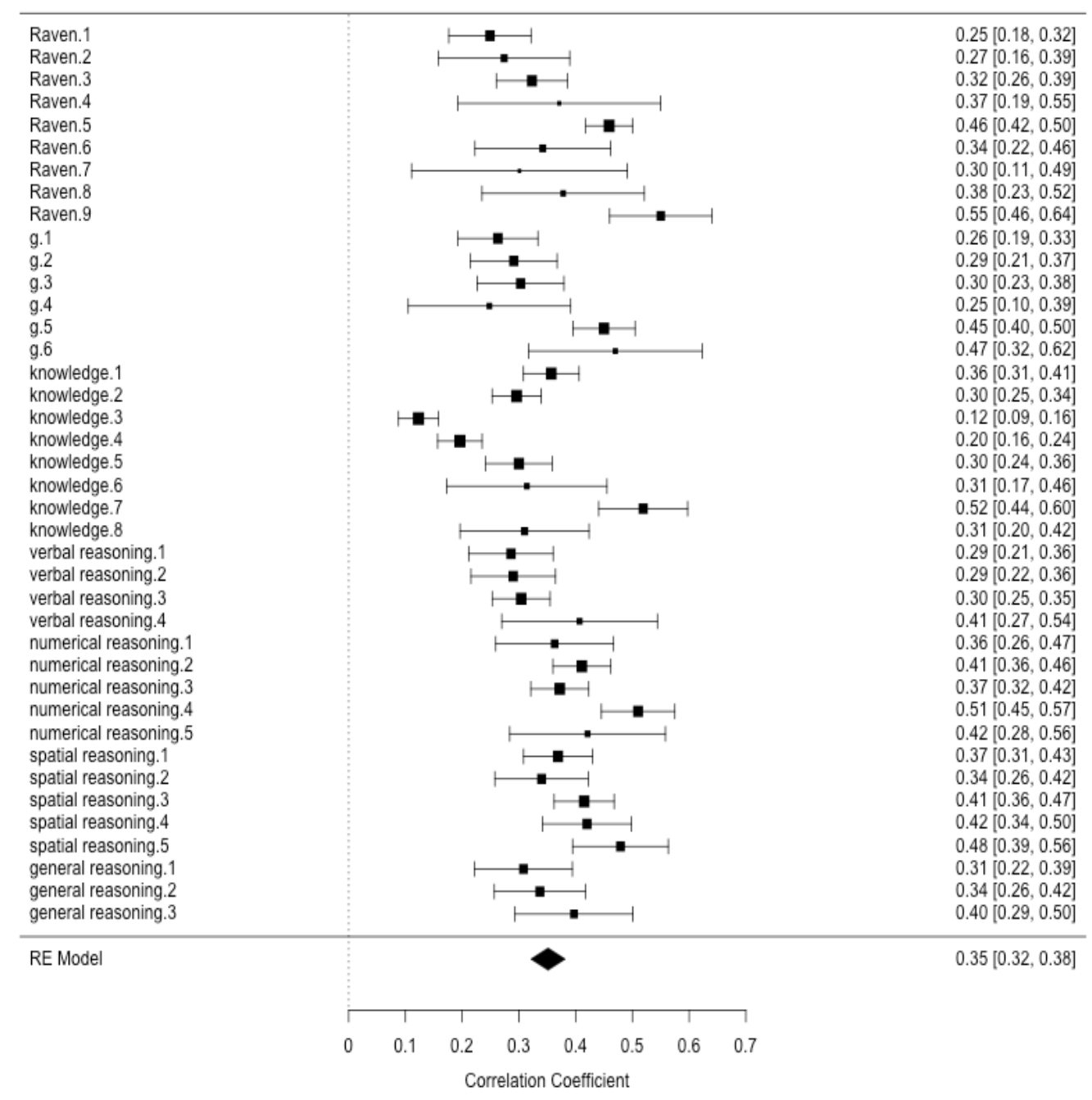

Figure 1 Forest plot: correlation coefficients and standard errors in 40 analyzed trials (Effect Size and $95 \%$ confidence interval). 


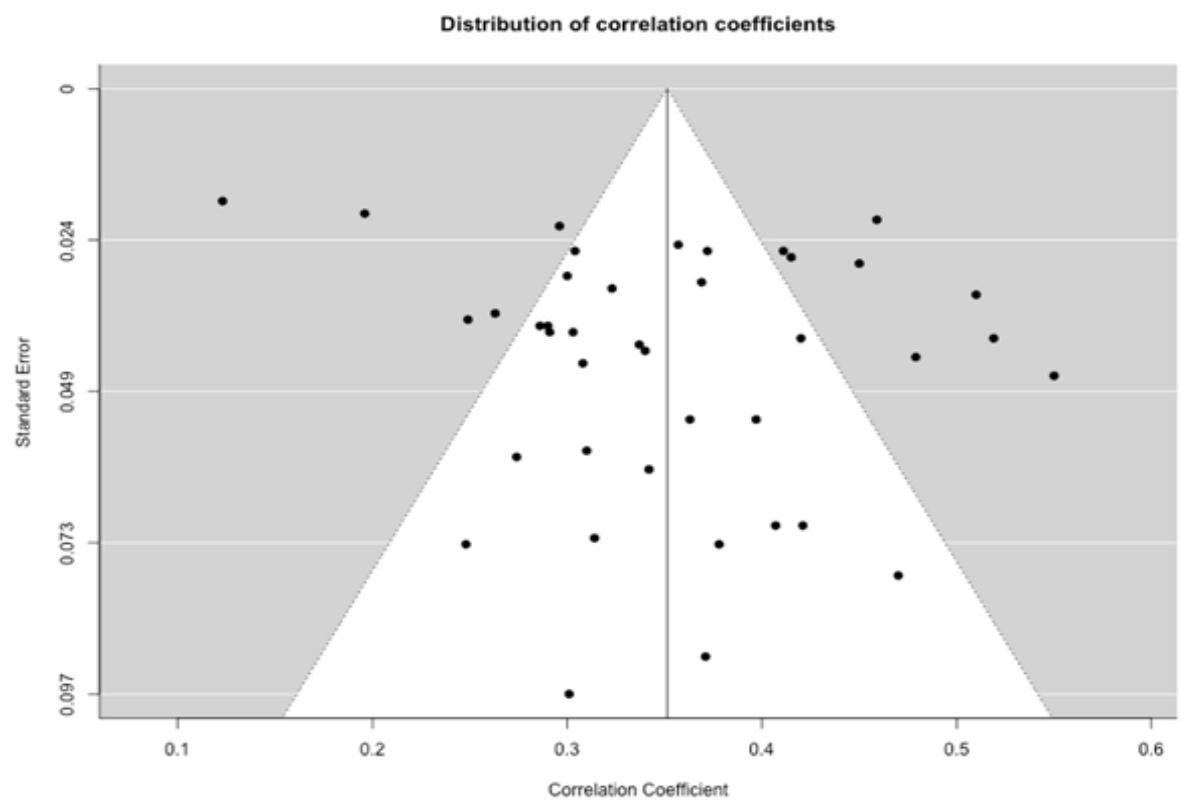

Figure 2 Funnel plot: symmetrical distribution of correlation coefficients.

\section{Discussion}

Publication bias is a serious threat to science, since it creates a false image of the observed phenomenon. Presence of publication bias in psychology is indicated by the results of replication studies (Open Science Collaboration, 2015). In these studies, less than $40 \%$ of the significant results were found with half the magnitude of the original effects. The main purpose of this analysis is to answer the question whether the results published in an influential paper, which has over 1000 citations (Ackerman, Beier, \& Boyle, 2005), were free of publication bias. The author expected to see an asymmetric distribution of results on the funnel chart, which would indicate the effect of publication bias. The hypothesis has not been confirmed in the results of the statistical analysis.
Although this meta-analysis did not bring forth a concern about the results of the original paper, we must be careful not to draw farfetched conclusions, considering the limitations of this study. This result does not prove that other meta-analyses of the relationship between fluid intelligence and working memory are free from publication bias. In this case, a specific set of observations was subjected to an analysis, therefore, we cannot generalize the conclusions to the whole realm of $G f$ and working memory relations. In order to determine the presence of publication bias in this field of research, a wide range of results published to date should be analyzed. Nevertheless, the results of this metaanalysis indicate clearly that the results of Ackerman, Beier, and Boyle (2005) are not influenced by publication bias.

The observed heterogeneity of the results (Figure 2) does not undermine the conclusions 
about the relationship between working memory and fluid intelligence. The heterogeneity is the result of introducing to the analysis tests that are not identical. Narrowing the set only to coefficients of one type would limit heterogeneity. However, the division into groups would contribute to obtaining funnel charts, where visible asymmetry is the result of division into groups, and not the actual impact of publication bias. Therefore, a decision was made to uphold the analysis of a heterogeneous set of results.

A symmetric distribution of correlation coefficients was observed in the funnel chart (Figure 2). The lack of a clear asymmetry suggests that an absence of publication bias in the metaanalysis of Ackerman, Beier, and Boyle (2005). A more detailed inspection of the funnel plots leads to the conclusion that low precision (high standard error value) and a high Pearson correlation coefficient were published less frequently. This is not surprising. Lack of precision of working memory capacity and fluid intelligence measures leads to underestimating the empirical Pearson correlation coefficient. We can suspect that researchers do not publish results in which the Pearson correlation coefficient exceeds standardized reliability measures for working memory capacity and fluid intelligence.

\section{References}

Ackerman, P. L., Beier, M. E., \& Boyle, M. O. (2005) Working memory and intelligence: The same or different constructs? Psychological Bulletin, 131(1), 30-60. doi: 10.1037/0033-2909.131.1.30

Bisson, J. F., Nejdi, A., Rozan, P., Hidalgo, S., Lalonde, R., \& Messaoudi, M. (2008). Effects of long-term administration of a cocoa polyphenolic extract (Acticoa powder) on cognitive performances in aged rats. British Journal of Nutrition, 100, 94-101, doi: 10.1017/S0007114507886375

Colom, R., Flores-Mendoza, C., \& Rebollo, I. (2003). Working memory and intelligence. Personality and Individual Differences, 34(1), 33-39. doi: 10.1016/ S0191-8869(02)00023-5

Colom, R., Rebollo, I., Palacios, A., Juan-Espinosa, M., \& Kyllonen, P. C. (2004). Working memory is (almost) perfectly predicted by g. Intelligence, 32(3), 277-296. doi: 10.1016/j.intell.2003.12.002

Corti, R., Flammer, A. J., Hollenberg, N. K., \& Luscher, T. F. (2009). Cocoa and cardiovascular health. Circulation, 119, 1433-1441. doi:10.1161/ CIRCULATIONAHA.108.827022

Daneman, M., \& Carpenter, P. A. (1980). Individual differences in working memory and reading. Journal of Verbal Learning and Verbal Behavior, 19 , 450-466. doi: 10.1016/S0022-5371(80)90312-6

Desideri, G., Kwik-Uribe, C., \& Grassi, D. (2012). Benefits in cognitive function, blood pressure, and insulin resistance through cocoa flavanol consumption in elderly subjects with mild cognitive impairment: The Cocoa, Cognition, and Aging (CoCoA) Study. Hypertension, 60, 794-801. doi: 10.1161/ HYPERTENSIONAHA.112.193060.

Dickersin, K., Chan, S., Chalmers, T. C., Sacks, H. S., \& Smith, H. (1987). Publication bias and clinical trials. Controlled Clinical Trials, 343-353. PMID: 3442991

Engle, R. (2002). Working memory capacity as executive attention. Current Directions in Psychological Science, 11, 19-23. doi: /10.1111/1467-8721. 00160

Gilbert, D. T., King, G., Pettigrew, S., \& Wilson, T. D. (2016). Comment on "Estimating the reproducibility of psychological science", Science, 351(6277). doi: $10.1126 /$ science.aad 7243 .

Jensen, A. R. (1998). The g factor. Westport, CT: Praeger.

Kane, M., Hambrick, D., \& Conway A. R. A. (2005). Working memory capacity and fluid intelligence are strongly related constructs: Comment on Ackerman, Beier, and Boyle (2005). Psychological Bulletin, 131, 66-71. doi: 10.1037/0033-2909.131.1.66

Kyllonen, P. C., \& Christal, R. E. (1990). Reasoning ability is (little more than) working-memory capacity?!, Intelligence, 14(4), 389-433. doi:10.1016/ S0160-2896(05)80012-1

Kyllonen, P. C. (2002). g: Knowledge, speed, strategies, or working-memory capacity? A systems perspective. In R. J. Sternberg \& E. L. Gigorenko (Eds.), The general factor of intelligence: How general is it? (pp. 415-445). Mahwah, NJ: Erlbaum.

Messerli, F. H. (2012). Chocolate consumption, cognitive function, and Nobel laureates. New England Journal of Medicine, 367(16), 1562-1564. doi: 10.1056/NEJMon1211064

Nurk, E., Refsum, H., Drevon, C. A., Tell, G. S., Nygaard, H. A., Engedal, K., \& Smith, A. D. (2009). Intake of flavonoid-rich wine, tea, and chocolate by elderly men and women is associated with better cognitive test performance. The Journal of Nutrition, 139, 120-127. doi: 10.3945/jn.108.095182 
Oberauer, K., Süß, H.-M., Wilhelm, O., \& Wittmann, W. W. (2008). Which working memory functions predict intelligence? Intelligence, 36(6), 641-652. doi: $10.1016 / \mathrm{j}$.intell.2008.01.007

Open Science Collaboration. (2015). Estimating the reproducibility of psychological science. Science, 349(6251). doi: 10.1126/science.aac4716

Rosenthal, R. (1979). The file drawer problem and tolerance for null results. Psychological Bulletin, 86(3), 638-641. doi: 10.1037/0033-2909.86.3.638

Sorond, F. A., Lipsitz, L. A., Hollenberg, N. K., \& Fisher, N. D. (2008). Cerebral blood flow response to flavanolrich cocoa in healthy elderly humans. Neuropsychiatric Diseases and Treatment, 4, 43340. PMID: 18728792

Sterne, J. A. C., Sutton, A. J., Ioannidis, J. P. A., Terrin, N., Jones, D. R., \& Lau, J. (2011). Recommendations for examining and interpreting funnel plot asymmetry in meta-analyses of randomized controlled trials. The BMJ, 343, 1-8. doi: 10.1136 bmj.d4002

Turner, M. L., \& Engle, R. W. (1989). Is working memory capacity task dependent? Journal of Memory and Language, 28, 127-154. doi: 10.1016/ 0749-596X(89)90040-5

Turner, E. H., Matthews, A. M., Linardatos, E., Tell, R. A., \& Rosenthal, R. (2008). Selective publication of antidepressant trials and its influence on apparent efficacy. New England Journal of Medicine, 358(3), 252-260. doi: 10.1056/NEJMsa065779.

Viechtbauer, W. (2010). Conducting meta-analyses in $\mathrm{R}$ with the metafor package. Journal of Statistical Software, 36(3), 1-48. URL: http://www.jstatsoft.org/ v36/i03/, doi: 10.18637/jss.v036.i03

The articles on the basis of which the correlation coefficients included in the meta-analysis were calculated:

Ackerman, P. L., Beier, M. E., \& Boyle, M. O. (2002). Individual differences in working memory within a nomological network of cognitive and perceptual speed abilities. Journal of Experimental Psychology: General, 131, 567-589. doi: 10.1037//00963445.131 .4 .56

Babcock, R. L. (1994). Analysis of adult age differences on the Raven's Advanced Progressive Matrices test. Psychology and Aging, 9, 303-314.

Babcock, R. L., \& Laguna, K. D. (1996). An examination of the adult age-related differences on the Raven's Advanced Progressive Matrices: A structural equations approach. Aging, Neuropsychology, and Cognition, 3(3), 187-200. doi: 10.2466/PMS.12. 3.283-288

Baddeley, A., Logie, R., \& Nimmo-Smith, I. (1985). Components of fluent reading. Journal of Memory
\& Language, 24, 119-131. doi: 10.1016/0749596X(85)90019-1

Baker, L. (1985). Working memory and comprehension: A replication. Bulletin of the Psychonomic Society, 23, 28-30. doi: 10.3758/BF03329770

Bayliss, D. M., Jarrold, C., Gunn, D. M., \& Baddeley, A. D. (2003). The complexities of complex span: Explaining individual differences in working memory in children and adults. Journal of Experimental Psychology: General, 132, 71-92. doi: 10.1037/00963445.132.1.71

Bichsel, J., \& Roskos-Ewoldsen, B. (1999). Imaginal discovery, working memory, and intelligence. Journal of Mental Imagery, 23(1-2), 17-34.

Chaiken, S. R., Kyllonen, P. C., \& Tirre, W. C. (2000). Organization and components of psychomotor ability. Cognitive Psychology, 40, 198-226. doi: 10.1006/cogp.1999.0729

Cherry, K. E., \& LeCompte, D. C. (1999). Age and individual differences influence prospective memory. Psychology and Aging, 14, 60-76. doi: /10.1037/ 0882-7974.14.1.60

Cherry, K. E., \& Park, D. C. (1993). Individual difference and contextual variables influence spatial memory in younger and older adults. Psychology and Aging, 8, 517-526. doi: 10.1037/0882-7974.8.4.517 Cantor, J., Engle, R. W., \& Hamilton, G. (1991). Shortterm memory, working memory, and verbal abilities: How do they relate? Intelligence, 15, 229-246. doi: 10.1016/0160-2896(91)90032-9

Cianciolo, A. T. (2001). Unitary or differentiated ability constructs for describing performance? Investigating individual differences and task characteristics. Unpublished doctoral dissertation, Georgia Institute of Technology, Atlanta.

Conway, A. R. A., Cowan, N., Bunting, M. F., Therriault, D. J., \& Minkoff, S. R. B. (2002). A latent variable analysis of working memory capacity, short-term memory capacity, processing speed, and general fluid intelligence. Intelligence, 30, 163-183. doi: 10.1016/ S0160-2896(01)00096-4

Conway, A. R. A., \& Engle, R. W. (1996). Individual differences in working memory capacity: More evidence for a general capacity theory. Memory, 4, 577590. doi: 10.1080/741940997

Cowan, N., Towse, J. N., Hamilton, Z., Saults, J. S., Elliott, E. M., Lacey, J. F., et al. (2003). Children's working-memory processes: A response-timing analysis. Journal of Experimental Psychology: General, 132, 113-132. doi: 10.1037/0096-3445.132. 1.113

Daneman, M., \& Carpenter, P. A. (1980). Individual differences in working memory and reading. Journal of Verbal Learning and Verbal Behavior, 19, 450-466. doi: 10.1016/S0022-5371(80)90312-6 
Daneman, M., \& Green, I. (1986). Individual differences in comprehending and producing words in context. Journal of Memory and Language, 25, 1-18. doi: 10.1016/0749-596X(86)90018-5

Daneman, M., \& Hannon, B. (2001). Using working memory theory to investigate the construct validity of multiple-choice reading comprehension tests such as the SAT. Journal of Experimental Psychology: General, 130, 208-223. doi: 10.1037/00963445.130.2.208

Daneman, M., \& Tardif, T. (1987). Working memory and reading skill re-examined. In M. Coltheart (Ed.), Attention and performance XII: The psychology of reading (pp. 491-508). London: Erlbaum. doi: 10.4324/9781315630427

Dixon, P., LeFevre, J., \& Twilley, L. C. (1988). Work knowledge and working memory as predictors of reading skill. Journal of Educational Psychology, $80,465-472$.

Dobson, S. H. (1998). Precursors of adult age differences in abstract and practical problem solving. Unpublished dissertation.

Earles, J. L. (1996). Adult age differences in recall of performed and nonperformed items. Psychology and Aging, 11, 638-648. doi: 10.1037/0882-7974.11. 4.638

Earles, J. L. K., Connor, L. T., Smith, A. D., \& Park, D. C. (1997). Interrelations of age, self-reported health, speed, and memory. Psychology and Aging, 12, 675-683. doi: 10.1037//0882-7974.12.4.675

Engle, R. W., Cantor, J., \& Carullo, J. J. (1992). Individual differences in working memory and comprehension: A test of four hypotheses. Journal of Experimental Psychology: Learning, Memory, and Cognition, 18, 972-992. doi:10.1037/02787393.18.5.972

Engle, R. W., Nations, J. K., \& Cantor, J. (1990). Is “working memory capacity" just another name for word knowledge? Journal of Educational Psychology, 82, 799-804. doi: 10.1037/0022-0663.82.4.799

Engle, R. W., Tuholski, S. W., Laughlin, J. E., \& Conway, A. R. A. (1999). Working memory, shortterm memory, and general fluid intelligence: A latent-variable approach. Journal of Experimental Psychology: General, 128, 309-331. doi: 10.1037/ 0096-3445.128.3.309

Fry, A. F., \& Hale, S. (1996). Processing speed, working memory, and fluid intelligence: Evidence for a developmental cascade. Psychological Science, 7 , 237-241. doi: 10.1111/j.1467-9280.1996. tb00366.x

Gilbert, D. K. (1995). The acquisition and utilization of spatial mental models for young and older adults. Unpublished dissertation, University of Memphis, Memphis, TN.
Graesser, A. C., \& Bertus, E. L. (1998). The construction of causal inferences while reading expository texts on science and technology. Scientific Studies of Reading, 2, 247-269. doi: 10.1207/ s1532799xssr02034

Hambrick, D. Z., \& Ëngle, R. W. (2001). Effects of domain knowledge, working memory capacity, and age on cognitive performance: An investigation of the knowledge-is-power hypothesis. Cognitive Psychology, 44, 339-387. doi: 10.1006/cogp.2001.0769

Jurden, F. H. (1995). Individual differences in working memory and complex cognition. Journal of Educational Psychology, 87, 93-102. doi: 10.1037/00220663.87.1.93

Kemper, S., \& Sumner, A. (2001). The structure of verbal abilities in young and older adults. Psychology and Aging, 16, 312-322. doi: 10.1037/08827974.16.2.312

Kyllonen, P. C. (1993). Aptitude testing inspired by information processing: A test of the four-scores model. Journal of General Psychology, 120, 375405. doi: 10.1080/00221309.1993.9711154

Kyllonen, P. C., \& Christal, R. E. (1990). Reasoning ability is (little more than) working-memory capacity?! Intelligence, 14, 389-433. doi: 10.1016/S01602896(05)80012-1

La Pointe, L. B., \& Engle, R. W. (1990). Simple and complex word spans as measures of working memory capacity. Journal of Experimental Psychology: Learning, Memory, and Cognition, 16, 1118-1133. doi: $10.1037 / 0278-7393.16 .6 .1118$

Larson, G. E., \& Alderton, D. L. (1990). Reaction time variability and intelligence: A "worst performance" analysis of individual differences. Intelligence, 14, 309-325. doi: 10.1016/01602896(90)90021-K

Larson, G. E., Merritt, C. R., \& Williams, S. E. (1988). Information processing and intelligence: Some implications of task complexity. Intelligence, 12, 131147. doi: 10.1016/0160-2896(88)90012-8

Larson, G. E., \& Saccuzzo, D. P. (1989). Cognitive correlates of general intelligence: Toward a process theory of g. Intelligence, 13, 5-31. doi: 10.1016/ 0160-2896(89)90003-2

Masson, M. E. J., \& Miller, J. A. (1983). Working memory and individual differences in comprehension and memory for text. Journal of Educational Psychology, 75, 314-318. doi: 10.1037/00220663.75.2.314

Miyake, A., Friedman, N. P., Rettinger, D. A., Shah, P., \& Hegarty, M. (2001). How are visuospatial working memory, executive functioning, and spatial abilities related? A latent-variable analysis. Journal of Experimental Psychology: General, 130, 621-640. doi: $10.1037 / 0096-3445.130 .4 .621$ 
Norman, S., Kemper, S., \& Kynette, D. (1992). Adults' reading comprehension: Effects of syntactic complexity and working memory. Journals of Gerontology: Series B: Psychological Sciences and Social Sciences, 47, 258-265. doi: 10.1093/geronj/47.4. P258

Oberauer, K., Süß, H.-M., Schulze, R., Wilhelm, O., \& Wittmann, W. W. (2000). Working memory capacity facets of a cognitive ability construct. Personality and Individual Differences, 29, 1017-1045. doi: 10.1016/S0191-8869(99)00251-2

Oberauer, K., Süß, H.-M., Wilhelm, O., \& Wittmann, W. W. (2003). The multiple faces of working memory: Storage, processing, supervision, and coordination. Intelligence, 31, 167-193. doi: 10.1016/ S0160-2896(02)00115-0

Oberauer, K., Schulze, R., Wilhelm, O., \& Süß, H.-M. (2005). Working memory and intelligence their correlation and their relation: Comment on Ackerman, Beier, and Boyle (2005). Psychological Bulletin, 131(1), 61-5; author reply 72-75. doi: 10.1037/ 0033-2909.131.1.61

Perlow, R., Jattuso, M., \& Moore, D. D. W. (1997). Role of verbal working memory in complex skil acquisition. Human Performance, 10, 283-302. doi: 10.1207/s15327043hup1003_4

Radvansky, G. A., Gerard, L. D., Zacks, R. T., \& Hasher, L. (1990). Younger and older adults' use of mental models as representations for text materials. Psychology and Aging, 5, 209-214. doi: 10.1037//08827974.5.2.209

Rosen, V. M., \& Engle, R. W. (1997). Forward and backward serial recall. Intelligence, 25, 37-47. doi: 10.1016/S0160-2896(97)90006-4

Rosenthal, R. (1979). The file drawer problem and tolerance for null results. Psychological Bulletin, 86(3), 638-641. doi: 10.1037/0033-2909.86.3.638

Rushton, J. P., Brainerd, C. J., \& Pressley, M. (1983). Behavioral development and construct validity: The principle of aggregation. Psychological Bulletin, 94, 18-38. doi: 10.1037/0033-2909.94.1.18

Salthouse, T. A. (1992). Why do adult age differences increase with task complexity? Developmental Psychology, 28, 905-918. doi: 10.1037/00121649.28.5.905

Salthouse, T. A., Babcock, R. L., Mitchell, D. R. D., Palmon, R., \& Skovronek, E. (1990). Sources of individual differences in spatial visualization ability. Intelligence, 14, 187-230. doi: 10.1016/01602896(90)90004-D
Salthouse, T. A., Mitchell, D. R. D., Skovronek, E., \& Babcock, R. L. (1989). Effects of adult age and working memory on reasoning and spatial abilities. Journal of Experimental Psychology: Learning, Memory, and Cognition, 15, 507-516. doi: 10.1037/02787393.15.3.507

Shah, P., \& Miyake, A. (1996). The separability of working memory resources for spatial thinking and language processing: An individual differences approach. Journal of Experimental Psychology: General, 125, 4-27. doi: 10.1037/0096-3445. 125.1.4

Singer, M., Andrusiak, P., Reisdorf, P., \& Black, N. L. (1992). Individual differences in bridging inference processes. Memory \& Cognition, 20, 539-548. doi: 10.3758/BF03199586

Spearman, C. (1904). "General intelligence" objectively determined and measured. American Journal of Psychology, 15, 201-293. doi: 10.2307/1412107 Stankov, L. (1994). The complexity effect phenomenon is an epiphenomenon of age-related fluid intelligence decline. Personality and Individual Differences, 16, 265-288. doi: 10.1016/01918869(94)90164-3

Tirre, W. C., \& Pena, C. M. (1993). Components of quantitative reasoning: General and group ability factors. Intelligence, 17, 501-521. doi: 10.1016/ 0160-2896(93)90015-W

Tucker, P., \& Warr, P. (1996). Intelligence, elementary cognitive components, and cognitive styles as predictors of complex task performance. Personality and Individual Differences, 21, 91-102. doi: 10.1016/0191-8869(96)00032-3

Tuholski, S. W. (1997). Examining the relationships among attentional resources, working memory, and fluid intelligence. Unpublished dissertation, University of South Carolina, Columbia.

Turner, M. L., \& Engle, R. W. (1986). Working memory capacity. Proceedings of the Human Factors Society, 30, 1273-1277. doi: 10.1177/ 154193128603001307

Turner, M. L., \& Engle, R. W. (1989). Is working memory task dependent? Journal of Memory and Language, 28, 127-154. doi: 10.1016/0749596X(89)90040-5

Verguts, T., \& De Boeck, P. (2002). On the correlation between working memory capacity and performance on intelligence tests. Learning and Individual Differences, 13, 37-55. doi: 10.1016/S10416080(02)00049-3 